\title{
Transition to practice: Supporting first year nurses within a collaborative faith based graduate program
}

\author{
Kylie P. Russell,; Tracey H. Coventry \\ School of Nursing and Midwifery, The University of Notre Dame Australia, Australia
}

Received: September 29, 2020

Accepted: December 23, 2020 Online Published: December 31, 2020

DOI: $10.5430 /$ jnep.v11n5p1

URL: https://doi.org/10.5430/jnep.v11n5p1

\begin{abstract}
Objective: Faith-based organisations play a major role in health care in Australia providing a unique service supported by compassionate and concerned staff. In response to the changing Australian health care landscape the increasing demands placed on first year registered nurses, a graduate program provided in partnership with a Catholic University, engages students in academic and clinical learning. The study aimed to determine if the provision of nursing care in the context of catholic faith and values provides first year nurses with a supportive learning environment.

Methods: This study used a mixed method explanatory sequential design in two phases: (1) quantitative online surveys sent to graduate nurses $(n=60)$ to report on their perceptions of work integrated learning prior to and during their first year of nursing at the private catholic hospital; and (2) focus groups were conducted to explore key themes in further detail. The evaluation occurred at both the halfway and the end point of the 12-month Graduate Program. Data was analysed using descriptive statistics and theming of the text data to identify emergent ideas.

Results: The findings suggest that the graduate nurses felt engaged with the programs academic and clinical learning outcomes. This was achieved in a supportive pastoral care environment underpinned by catholic faith and values.

Conclusions: The Graduate Program in collaboration with a Catholic University School of Nursing and Midwifery has provided a positive learning experience and support structure for its first year registered nurses with the achievement of a formally recognised qualification.
\end{abstract}

Key Words: Nursing education, Newly qualified nurses, Catholic healthcare, Catholic university

\section{INTRODUCTION}

The Australian health care setting is part of a global entity that is in a state of constant change, and described as erratic and affected by a large number of adverse factors and challenges. ${ }^{[1]}$ Increasing patient acuity, complex conditions, technology, consumer expectations and the financial constraints related to health service provision are just a few of the competing demands for time and resources. ${ }^{[2]}$ Every health care organisation aims to provide safe, quality and cost effective care by competent and well trained staff. In this context the novice graduate nurse begins their professional journey, with their nursing practice significantly impacted by the culture of the organisation and clinical environment. ${ }^{[3]}$ This mixed method study aimed to evaluate a graduate program provided within the context of catholic faith and values. Opened ended questions in an online survey and focus group interviews with participants focused on this program aspect. Closed ended questions using a validated work integrated learning tool to capture information about the learning experience. The study site, one of the largest providers of private

\footnotetext{
* Correspondence: Kylie P. Russell; Email: kylie.russell@ nd.edu.au; Address: School of Nursing and Midwifery, The University of Notre Dame Australia, Australia. 
health care in Australia, is a not for profit hospital providing care within the context of catholic faith and values.

Faith-based organisations play a major role in health care in Australia where local populations encounter a unique service supported by compassionate and concerned staff who work in opposition to the inflexibility that often exists in contemporary health care. This action of service to others is evident in the relationships created in the pursuit of the common good that places patient quality of care as the primary consideration in nursing decision making and interactions. ${ }^{[4]}$ In response to the changing Australian health care landscape, and the increasing demands placed on first year registered nurses, in February 2016 the study site introduced their 'Pathways to Practice' model to support nursing professional and clinical development. The implementation of the program, provided in partnership with a Catholic University engages students in academic and clinical learning to consolidate and support their first year of practice. On successful completion of both academic and clinical assessments, the Graduate Certificate in Clinical Nursing (GCCN) is awarded.

This 12-month Program for first year registered nurses incorporates a comprehensive orientation program, various clinical rotations, paid study days, a preceptorship (peer) support program and on-line learning resources. In addition, this collaboration provides an atmosphere for students in which community and pastoral care form the foundation for student success and growth as a comprehensive registered nurse. The course provides a pathway into further study at Diploma or Master level.

The Graduate Certificate program is based within the framework of Work Integrated Learning. The term 'work integrated learning' (WIL) describes the collaboration between higher education institutions with industry to provide workplace learning. ${ }^{[5]}$ Workplace learning supports the application of theory to practice which develops the essential skills, experience and an understanding of the 'real' world of the chosen profession. ${ }^{[6]}$ The term is used in the graduate nursing context to describe the intersection of the GCCN curriculum with the health services organisation's clinical capacity for practice. Newly qualified registered nurses in their first year of nursing are able to participate in formal academic learning in the clinical environment. A variety of learning and teaching strategies are incorporated through the partnership of the health care organisation's nurse educators and the university program coordinator. Postgraduate WIL invests in quality and safe patient outcomes through the clinical, professional and academic capacity for practice of registered nurses. ${ }^{[7]}$

The nurses' role as a health care professional is unique in relation to the time spent with the patient at the point of care. In particular, first year registered nurses, in their transition from the student role to practitioner, can experience a range of emotions and professional challenges. ${ }^{[8]}$ This significant time of learning, adjustment and application of theory to practice requires the presence of resilient professional education and clinical support, positive relationships and a healthy workplace environment for successful completion of the first year of nursing. ${ }^{[9]}$ The formal course evaluation of the program considered the impact of WIL within a framework of catholic faith and values. The study sought to describe and understand the influence of catholic faith and values on the learning experiences of the graduate nurses in their first year of nursing. In addition, this study aligns with the health services mission and commitment to quality patient care and investment in supporting staff, and the university's objects of pastoral care and training for the professions.

\section{Methods}

A mixed method explanatory sequential design ${ }^{[10]}$ was used whereby the quantitative phase findings were used to inform the subsequent qualitative phase, as described in Figure 1.

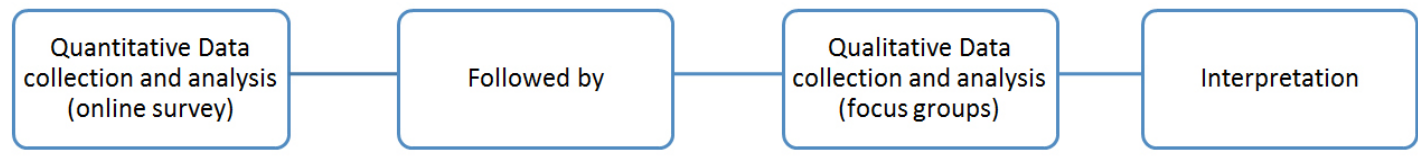

Figure 1. Research design

This design is well-suited for the researchers to explain the reasons for the graduate nurses understanding of the support they received within a collaborative faith based education program. The evaluation occurred at both the halfway and the end point of the 12-month Graduate Program. The online survey was disseminated near the completion of the first clinical rotation (at approximately five months) and towards the end of the 12-month program, followed in both instances by the post survey focus group interview, as articulated in the below Figure 2.

\subsection{Participants}

The population were newly qualified registered nurses employed in the Graduate Program at the study site in Australia. 
The Graduate Program in 2016 had two intakes:

- Group 1 February/April $2016(n=47)$

- Group 2 August $2016(n=13)$

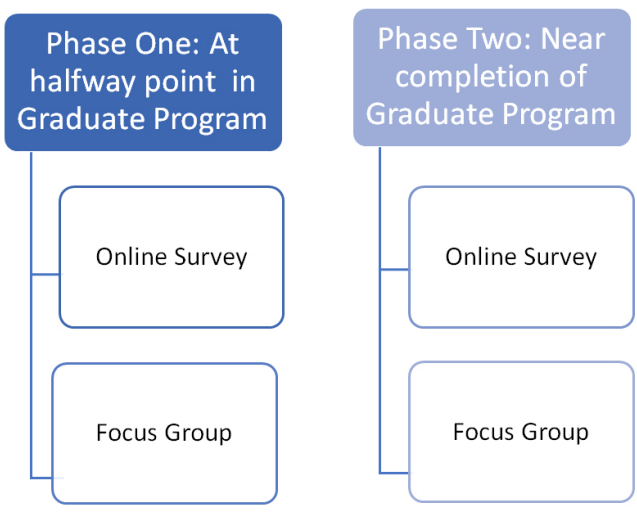

Figure 2. Quantitative and qualitative data collection phases

\subsection{Sample selection}

The online surveys used a convenience sampling technique $^{[10]}$ of all graduate nurses employed in the 2016 health service Graduate Program $(n=60)$. The focus group interview participants consisted of a convenience sample of graduate nurses attending an organised study day and invited to participate during study time. The sample size was determined based on sufficient information gathered from the nurses in the focus group to achieve data saturation. ${ }^{[11]}$ The participants were contacted via their health service and university email with an invitation and link to the online survey. A subsequent email was sent prior to the study day to invite participants to attend the one-hour focus group interview to explore key themes in further detail and enrich the survey findings.

\subsection{Data collection}

The quantitative and qualitative data collection included the online survey incorporating close ended and Likert scale questions about the participants' experience of WIL in their first year of nursing. The University of Tasmania's WIL Evaluation Tool was used with permission from the WIL project team. The validated WIL Evaluation Tool measures and reports on the graduate's perceptions of their learning including preparation prior to commencing WIL, engagement with active learning while on WIL and opportunities to develop a professional sense of self. ${ }^{[12]}$ For the purpose of this study, and focus of this paper, an additional text entry question collected information on the participants' perspec- tive on the impact and value of a graduate program within a faith-based organisation.

The focus group data collection technique used interviews with a group of five to 10 graduate nurses to elicit opinions and experiences simultaneously. ${ }^{[11]}$ The focus group interviews were audio recorded and transcribed. The online survey findings informed the direction of discussion, allowing the interviewer the flexibility to follow topics in-depth, ask additional questions and expand on issues raised by the participants with the freedom to seek clarification. ${ }^{[13]}$

\subsection{Data analysis}

The WIL Evaluation Tool provided quantitative data in a formatted report with statistical data and graphs. Open ended questions responses were reported in text format ${ }^{[12]}$ and included in the qualitative data analysis process. The qualitative data, including the open-ended survey questions and the focus groups, was examined to identify emergent ideas and themes. ${ }^{[14]}$ Microsoft Word was used to manage the data, ideas and create visual representations for the presentation of relationships.

Research approval was granted by both the University and Health Service Human Research Ethics Committee. All participants were provided with an information sheet and consent and were free to withdraw from the study at any time. No identifying details were collected to ensure participant confidentiality.

\section{Results}

\subsection{Quantitative findings}

The quantitative findings provided statistical support for the program. The first two questions of the online survey confirmed the unit of enrolment in the GCCN and the organisation. The following two questions used a Likert scale to indicate the level of preparedness and learning prior to and during the graduate program. Question 3 does not reflect only on the health service, as it incorporates both the university experience and the orientation to the health service. Question 4 included a number of sub questions that related to the participant's opportunity to engage in learning. The responses for each of these questions articulate that in most cases the participants felt that they were able to engage positively in the learning experience during their graduate program. Those elements whereby participants felt a lack of engagement related to opportunities to apply their knowledge and actively engage in clinical learning. These findings are summarised in Table 1. 
Table 1. Work Integrated Learning Survey Item $3 \& 4(\%)$

\begin{tabular}{|lllll|}
\hline Question 3: Prior to starting this WIL to what extent did you... & Not at all & Somewhat & A Great Deal & Not Sure \\
\hline Feel prepared for your WIL in terms of your learning & 5 & 77 & 18 & 0 \\
\hline Question 4: During this WIL experience to what extent did you... & Not at all & Somewhat & A Great Deal & Not Sure \\
\hline Apply (i.e. put into practice) your prior knowledge & 16 & 44 & 38 & 2 \\
\hline Build on your prior knowledge & 16 & 44 & 40 & 0 \\
\hline $\begin{array}{l}\text { Actively engage in learning (e.g. sought information independently, } \\
\text { negotiated learning opportunities etc.) }\end{array}$ & 21 & 39 & 40 & 0 \\
\hline $\begin{array}{l}\text { Feel supported in your learning by your primary PEP } \\
\text { supervisor/preceptor (or equivalent) }\end{array}$ & 7 & 46 & 47 & 0 \\
\hline $\begin{array}{l}\text { Have opportunities to develop and apply your ethical principles (e.g. } \\
\text { client confidentiality, respect for others etc.) }\end{array}$ & 0 & 6 & 94 & 0 \\
\hline Achieve the unit learning outcomes & 0 & 46 & 51 \\
\hline Achieve your personal learning goals & 3 & 41 & 56 \\
\hline
\end{tabular}

The survey findings suggested that the program was of benefit to the graduates learning journey. In particular, through the support provided by preceptors and staff to achieve learning outcomes which further supported the application of ethical practice, critical thinking principles, problem solving and communication skills and ensured a general awareness of the workplace cultural and role expectations. These findings are depicted in Table 2.

Table 2. Work Integrated Learning Survey Item 5 (\%)

\begin{tabular}{|lllll|}
\hline Question 5: to what extent have you developed your... & Not at all & Somewhat & A Great Deal & Not Sure \\
\hline Knowledge of the field you were studying & 0 & 23 & 77 & 0 \\
\hline Critical thinking skills & 0 & 29 & 67.5 & 3.5 \\
\hline Ability to solve complex problems & 0 & 49 & 71 & 0 \\
\hline Ability to work with others & 0 & 27.5 & 72.5 & 0 \\
\hline Confidence to learn independently & 0 & 21.5 & 78.5 & 0 \\
\hline Written communication skills & 0 & 44.5 & 55.5 & 0 \\
\hline Ability to interact with others in respectful manner & 0 & 34 & 73.5 & 0 \\
\hline General workplace awareness & 0 & 26.6 & & 0 \\
\hline
\end{tabular}

The concepts from the online survey were explored in further detail in the focus group sessions both in phase one and two.

\subsection{Qualitative findings}

Going straight from university to working at a hospital, I think the program was great... you were kind of taken under the hospital's wing.

Findings from the qualitative phase of the study across the 12 month program are articulated in Figure 3, and discussed in further detail.

\subsubsection{Health service attributes}

[The health service] has been wonderful and supportive and utilizes their values and mission statement.

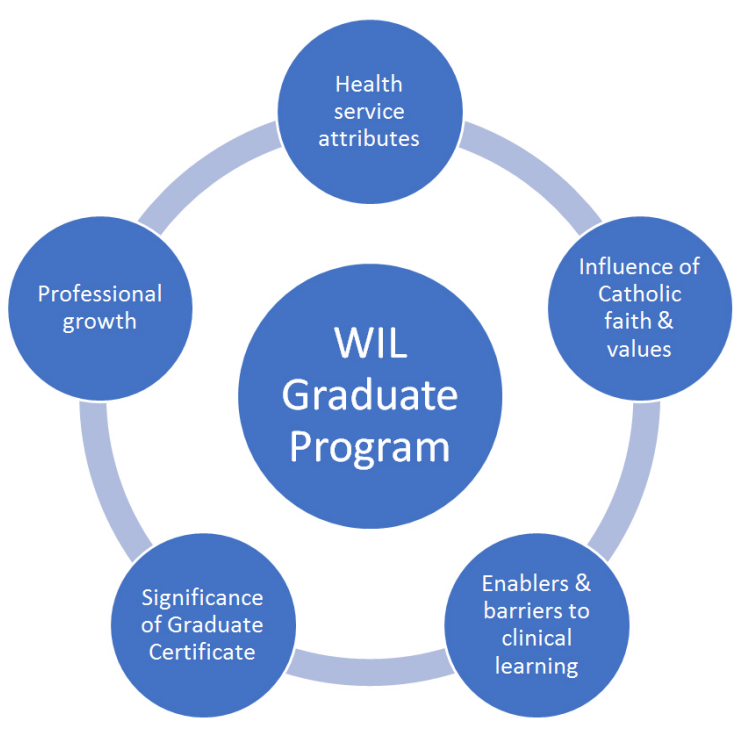

Figure 3. Qualitative Research Findings 
Across the program participants described the attributes of the health service, focusing on pastoral care and the catholic faith and values. This was particularly evident in the first half of the program in relation to choosing a health service to undertake a graduate program and the experience of the job application process.

That was like the main difference with the grad interviews. .. the public sector, they were more like scenario based questions... then [xxx] was more like beliefs and values and 'would you fit in'... it was more based on who you are as a person.

Other participants shared this similar experience "Yeah, because like the public ones were just more like cut and dry in terms of 'what would you do in a situation', rather than who you are as a person" and "here's your task. How would you do it?"

Additionally participants spoke of being at the health service previously as a student or employee, and felt that the organisation had been welcoming and supportive. "I liked the hospital, I did prac here and I really liked it. I think it is a good environment" and "I already worked for [the health service], so I already liked the company... it made sense to $m e ”$.

The opportunity to participate in the Graduate Certificate also provided an additional incentive, "The certificate was definitely something for me" and "I liked that they put us through uni, its good for our future" and "I got into [xxx] grad program as well, so I got to choose, and one of the reasons why I chose here was because of the postgraduate studies". Participants felt that the health service in providing access to the university demonstrated a supportive workplace that was prepared to invest in their staff.

\subsubsection{Influence of Catholic Faith and Values}

There is a certain level of commitment to faith that really reflects in the workplace.

Participants described how the catholic status of the health service flowed through to the ward level "When you were on the ward, the values were definitely there". A number of participants commented on the visible impact of the catholic sisters, priests, and pastoral care providers, "they have the Sisters wandering around", and "they have a priest actually go around the wards", it was also noted that "they do communion". The participants also talked about the influence of the catholic faith on pastoral care. "It's really nice here having the pastoral care on call all the time for support" and "the counsellors and pastoral care people, they sort of have the

Published by Sciedu Press time to sit with them for longer". Participants felt that these services provided a unique experience for patients, that as nurses they did not always have the time to meet, due to the complexity of patient care. Instead, having these resources, enabled them to focus on good patient care.

\subsubsection{Enablers and Barriers to Clinical Learning}

The managers, they really display the values, and they make you feel like you're a family on the wards, and the Staff Development Nurses as well.

Participants shared their experiences of being able to easily seek out help, "for the most part, it's quite supportive", and "there's a lot of support if you need it". In particular the Learning and Development (L\&D) Nurses and Educators were seen as a supportive network, who were available and provided opportunities to learn, " $L \& D$ they are really good at supporting you, and helping you, whenever you really need it" and "the L\&D was extremely supportive and helpful in seeking out development opportunities."

Other elements that supported the learning journey of the graduate nurses included opportunities to work in different areas and care for a variety of patients, "There was a good range of patients and medical conditions". The provision of "hands on study days" in the program provided opportunities to meet with other graduates, and learn from experts. Whilst the ward nurses supported the application of theory to practice, they were seen as integral to providing an environment in which graduates felt they were able to learn and seek help, "The immediate workplace i.e. ward environment at [the health service] helped me immensely". Other supportive aspects described in the survey that enhanced the structure of the Graduate Program included: "Self-Development Learning Package”, "Information booklets", "Social network”, "Critical thinking patient assessment", and "Having supportive nurses on the ward".

However at times the graduates felt frustrated when these enablers to support their learning and delivery of patient care were absent. In particular this occurred when L\&D nurses were not available, and the complexity of patient care resulted in less time to engage in learning. "Heavy workload on myself and learning support staff removing learning opportunities". In some ward areas L\&D nurses were not full time employees, graduates in particular felt this key position to support learning needed to be available, "More regular access to learning and development staff". Graduates also struggled with the concept of a strict financial budget, which was very different from working within the public health system. 
I notice on the ward, in the budget, they are quite strict... any money they make goes to their outreach program, and so I guess when you think about it, it's a good thing, but at the same time they're always very budget conscious.

Participants were also concerned about access to health care resources for the delivery of patient care, "if you want an expensive one [dressing product] you have to call up people... you have to order it specially". This extended to seeking a patient's permission to order items, which was a very different experience "permission from the patient and the doctor". These differences in process resulted in frustration and a loss of autonomy in determining nursing care.

\subsubsection{Significance of the GCCN}

People keep telling me, the more you do and get yourself involved with the better. I'd say the better it looks on your resume, but it's definitely just better for you in general. I guess the more you know as a nurse... the better you're going to be.

Participants articulated that the Graduate Program was enhanced by the alignment to the GCCN. Comments reflected on how the assignments encouraged them to look deeper at aspects of their care and how the hospital worked, as well as the sense of achievement with completing the additional tasks required and how this looked to outsiders. The assignments in particular encouraged students to take note of what was happening around them and why, "Makes you think about stuff". Another participant in particular liked the benefit of real work learning,

I actually liked doing the assignment because at uni you are doing an assignment based on theory, whereas now we are doing it based on stuff that we have actually do. And it like its real life, it's not theory kind of thing ... we are actually doing an audit and stuff that we have actually done and we are involved in it.

Participants articulated how the course would assist with future opportunities, "Looks good on the resume", and "Shows you how you can do study on top of your workload as well". Others felt that it would make then more competitive when seeking out opportunities at the end of the graduate program, "You may be able to apply for jobs that other people who are just coming out of their grad program can't" and "In terms of jobs in the future I always see on JOBS WA they're looking for post grad qualifications".
Students were divided by the additional burden of formal study on the graduate program and what they thought the expectations of postgraduate study would be, "big difference between undergraduate then postgraduate" and "working fulltime and still having to do assignments is hard".

You'd come home from a really hard seven hour shift. .. and I've got an assignment I really need to do... I can't sit down and watch my favourite TV show... I guess sacrificing that now at an early age, I guess it will set us up.

Others, found the workload was not a concern. "It's not a massive workload throughout the year" and "working and studying at the same time, it's a good transition”.

Despite some of these hurdles, participants articulated that they could see the benefit of the certificate in relation to their nursing career, "I would probably say even the grad cert that we've done was the most important thing, because you come out with the extra qualification". Participants in general agreed that the additional workload was of benefit in the long term with the awarding of a formal qualification that can be built upon. This provided confidence to engage in further study and had led them to consider that further study may be an option. In particular participants felt that the program demonstrated the health services commitment to growing their own staff, which flowed through to patient care outcomes. This was aligned with the organisations dedication to pastoral care and the universities object to train the professions.

\subsubsection{Professional growth}

I do feel that the core values and mission do lead to a more cohesive and positive workforce.

As the graduates neared the end of their 12-month program, there was an overall sense of achievement. Many felt that the program provided a transition into nursing that was not as daunting as it would have been without the program, with opportunities to complete the study days and engage in learning, "They are a grad, they're new, let's give them this opportunity'... its allowed us to do things that we may not have been able to do".

The participant's plans for the future were unknown. With no permanent positions available at the end of the program, there was a sense of uncertainly, "There's a job freeze, so none of us are getting jobs" and "it's very disheartening to constantly hear from people 'oh are you worried about getting a job after this?" Despite this there was a desire with the group to stay with the health service on completion of

ISSN 1925-4040 E-ISSN 1925-4059 
their program if they could, and to stay in nursing, with goals about future possibilities in mind.

\section{Discussion}

Graduate programs offered in Western Australia (WA) are formal transition programs for newly qualified nurses in their first year of practice. An integrative review by Missen et al. ${ }^{[15]}$ collated the standard curriculum content for transition programs across Australia. This content was inclusive of evidence based practice and patient safety and risk minimisation practices embedded in orientation, supernumerary time, study days, clinical support and supervised clinical practice within a variety of specialities. ${ }^{[15]}$ The graduate program model described in this study followed the standard content, thereby ensuring the newly qualified nurses were able to meet their registration standards to 'maintain, improve and broaden their knowledge, expertise and competence, and develop the personal and professional qualities needed throughout their professional lives'. ${ }^{[16]}$

Significantly, the alignment of this program with the academic rigor of the GCCN maximised the graduate's professional growth through the range of flexible and supported learning and resources available through the university partnership. Massimi et al. ${ }^{[17]}$ emphasise the benefit of additional postgraduate studies integrated with clinical practice, which further contributes to increased clinical confidence in decision making and broadens skills and knowledge. Additionally, the model provided unique opportunities — beyond the standard transition to practice framework-through engagement in peer networking across hospital sites and supported participation in organisational nursing research. Initiatives such as these also provided a competitive point of difference from other available graduate programs and encouraged high quality applicants. Thus, programs that enrich the graduate experience are an investment in nurse retention, reduced turnover and lead to improved financial savings beyond the transition year. ${ }^{[18-21]}$

The recruitment for the graduate program included a consideration of personal values related to the ability to integrate into the workforce in order to deliver the holistic and respectful patient care expected by patients who choose a faith-based health care service. ${ }^{[18,20]}$ However, the focus for graduates on completing their undergraduate degree was to gain a position in a graduate program. This difficulty was frequently expressed and appeared in direct relation to the current oversupply of graduated new nurses in contrast to the limited number graduate program places. ${ }^{[22,23]}$ For this reason, the graduate's decision to accept a position in the graduate program may have been unrelated to the health service stated mission and values. Any graduate program

Published by Sciedu Press position was highly regarded in light of the need for employment and the desire to transition from a novice to a competent professional nurse following completion of undergraduate studies. ${ }^{[24]}$ Specifically, the graduates articulated the important aspects of their career progression as the contribution of the L\&D staff who provided the desired mentorship, ${ }^{[8]}$ the protected time to process new learning enhanced by debrief of experiences in a safe environment ${ }^{[9]}$ and the opportunities for consolidating new skills in a variety of specialty areas. ${ }^{[25]}$

Barriers to the graduate's professional growth were not unexpected. A review by Bakon et al. ${ }^{[26]}$ depicted the variability in the specified content of graduate transition programs, including insufficient time for ward orientation and allocated supernumerary periods which had a significant impact on graduate satisfaction and subsequent retention. Furthermore the attributes of contemporary health care such as high patient acuity, rapid patient turnover and the increase in complex and chronic patient conditions made graduate willingness to learn and their ability to adapt to their new work setting challenging. ${ }^{[27]}$ In common with other postgraduate students the expectation of a higher level of study and advanced computer skills required a sacrifice of leisure and family time, linked with increased stress when unexpected family demands, such as illness occurred. ${ }^{[28]}$ The graduates also stated there was insufficient time for preceptorship and attendance at formal or informal education due to the priority of unfinished patient care related to organisational pressures such as short staffing. ${ }^{[2]}$ Thus, the reality of the clinical setting despite the context of foundational catholic principles, impacted on the graduates clinical, social and emotional wellbeing consistently throughout the program. ${ }^{[30]}$ On reflection, the graduates were grateful for the opportunity to transition into nursing with a structured approach to learning. However, their tangible apprehension was directed to the limited permanent registered nurse positions available for post-program employment both within the organisation and in other WA health care facilities. The graduates' reality was in opposition to the frequently espoused predicted shortage of nurses, with confirmation through anecdotal experiences and statistics of the continual decline in full time employment. ${ }^{[31]}$

Pastoral care was easily identified by the graduates as the emotional and spiritual support provided at ward level by the health service counsellors and pastoral care staff. Catholic Health Australia ${ }^{[32]}$ identified this approach as complimentary to care provided for physical illness and integral to Catholic health care. Baldacchino ${ }^{[33]}$ suggested the impact of this spiritual role modelling in the clinical environment helped shaped the practice of compassionate care: a requirement in catholic health services that foster holistic patient 
care delivered by caring professionals. This spiritual leadership was clearly observed in the actions of the Sisters, Priests, counsellors and pastoral care staff whose attentive roles allowed them to spend time with patients that graduates felt they did not have due to their heavy workload. Contemporary health care challenges where financial viability directly affects nurse staffing and workload ${ }^{[34]}$ and subsequently time management, ${ }^{[35]}$ impact on nurses providing time rich individualised patient care. Consequently this negatively impacts the compassion that was once seen as the motivation for being a nurse and has now become the remit of other caring professions. ${ }^{[36]}$ 'Good patient care' was a concept clearly expressed by the graduates as a product of their own core values of caring - refined through their undergraduate years and experiences in nursing practice-not just an echo of that espoused by the health service. ${ }^{[37]}$ However, the added value of the pastoral care team in a sustainable caring culture of relationship and communication within the health service was highly valued as a supportive measure for the graduates own transition practice and emotional wellbeing. ${ }^{[18]}$

\section{Limitations}

The GCCN is available at various public and private hospitals in Western Australia. This study only involved participants employed at a catholic health service, with the aim to determine the impact of catholic faith and values on the graduate nurse experience.

\section{Conclusion}

The Graduate Program in collaboration with a Catholic University School of Nursing and Midwifery has provided a positive learning experience and support structure for its first year registered nurses. The 12-month program provided a point of entry into the health service that supported this group of novice nurses as they developed confidence and ability in their practice. The opportunity to work in multiple clinical areas provided different experiences that grew confidence and ability; the learning and development nurses and study days supported this. The Graduate Certificate of Clinical Nursing, a formally recognised qualification provided a sense of achievement for the additional work undertaken during the program, and promoted critical thinking of nursing actions and a greater understanding of the wider health care sector standards and processes. The underlying catholic faith and values of both the health service and university provided an environment in which these graduates felt supported and encouraged during this time of professional growth.

\section{ACKNOWLEDGEMENTS}

The authors wish to acknowledge the graduates who gave their time willingly to share their insights, the health service for supporting this research and the University of Tasmania for use of the WIL evaluation tool and analysis.

\section{CONFLICTS OF INTEREST DisClOSURE}

The authors declare that there is no conflict of interest.

\section{REFERENCES}

[1] Petrich L. Challenges and opportunities for integration in health systems: an Australian perspective. Journal of Integrated Care. 2013; 21(6): 347-359. https://doi.org/10.1108/JICA-09-2013-0 037

[2] Briggs D. Challenges for Health Systems: Australian Perspectives. Public Administration and Policy. 2017; 20(1): 06-17.

[3] $\mathrm{Ohr} \mathrm{H}$. The organisational socialisation of new graduate nurses and midwives within three months of their entrance into the health workforce. Australian Journal of Advanced Nursing. 2020; 37(2): 3-10. https://doi.org/10.37464/2020.372.102

[4] Mannion D. Understanding organisational culture for healthcare quality improvement. BMJ. 2018; 363: k4907-k4907. PMid:30487286 https://doi.org/10.1136/bmj.k4907

[5] Smith W. Unpacking the learning-work nexus: "priming" as lever for high-quality learning outcomes in work-integrated learning curricula. Studies in Higher Education. 2015; 40(1): 22-42. https: //doi.org/10.1080/03075079.2013.806456

[6] Drysdale M, McBeath M, Johansson K, et al. Psychological attributes and work-integrated learning: an international study. Higher Education, Skills and Work-Based Learning. 2016; 6(1): 20-34. https://doi.org/10.1108/HESWBL-02-2015-0004
[7] $\mathrm{Ng}$ E. Exploring factors affecting registered nurses' pursuit of postgraduate education in Australia. Nursing \& Health Sciences. 2016; 18(4): 435-441. PMid:27192963 https://doi.org/10.1111/nh s. 12289

[8] Missen K, McKenna L, Beauchamp A. Satisfaction of newly graduated nurses enrolled in transition-to-practice programmes in their first year of employment: a systematic review. Journal of Advanced Nursing. 2014; 70(11): 2419-2433. PMid:24989716 https : //doi.org/10.1111/jan.12464

[9] Henderson A, Ossenberg C, Tyler S. 'What matters to graduates': An evaluation of a structured clinical support program for newly graduated nurses. Nurse Education In Practice. 2015; 15(3): 225-231. PMid:25665461 https://doi.org/10.1016/j.nepr.2015.01 .009

[10] Creswell J, Plano Clark V. Designing and conducting mixed method research (3rd ed.). Los Angeles: Sage Publications Inc.; 2018.

[11] Polit D, Beck C. Essentials of nursing research: appraising evidence for nursing practice (9th ed.). Philadelphia, PA: Wolters Kluwer. 2018.

[12] University of Tasmania. WIL Evaluation User Guide. Australian Collaborative Education Network. 2016. Available from: http://acen.edu.au/wp-content/uploads/2017/03/WIL -Evaluation-Tool-User-Guide.pdf 
[13] Doody O, Noonan M. Preparing and conducting interviews to collect data. Nurse Researcher. 2013. 20(5): 28-32. PMid:23687846 https://doi.org/10.7748/nr2013.0520.5.28.e327

[14] Clarke V, Braun V. Teaching thematic analysis. Psychologist. 2013; 26(2): 77-101. 120-123. Psychology and Behavioural Sciences Collection.

[15] Missen K, McKenna L, Beauchamp A. Registered nurses' perceptions of new nursing graduates' clinical competence: A systematic integrative review. Nursing \& Health Sciences. 2016; 18(2): 143-153. PMid:26592371 https://doi.org/10.1111/nhs.12249

[16] Nursing and Midwifery Board of Australia. Continuing professional development guidelines. 2016. Available from: http://www.nursingmidwif eryboard.gov.au/Codes-Gui delines-Statements/Codes-Guidelines.aspx

[17] Massimi A, Marzuillo C, Di Muzio M, et al. Quality and relevance of master degree education for the professional development of nurses and midwives. Nurse Education Today. 2017; 5354-60. PMid:28445791 https://doi.org/10.1016/j.nedt.2017.04 .012

[18] Edward K, Giandinoto J, Mills C, et al. Nursing Practices in Catholic Healthcare: A Case Study of Nurses in a Catholic Private Hospital. Journal of Religion and Health. 2017. PMid:29116581 https: //doi.org/10.1007/s10943-017-0520-z

[19] Friedman M, Delaney M, Schmidt K, et al. Specialized new graduate RN pediatric orientation: A strategy for nursing retention and its financial impact. Nursing Economics. 2013; 31(4): 162-170. https://www.ncbi.nlm.nih.gov/pubmed/24069715

[20] Kutney-Lee A, Melendez-Torres G, McHugh M, et al. Distinct enough? A national examination of Catholic hospital affiliation and patient perceptions of care. Health Care Management Review. 2014; 39(2): 134-144. PMid:23493045 https://doi.org/10.1 097/HMR. 0b013e31828dc491

[21] Twigg D, McCullough K. Nurse retention: A review of strategies to create and enhance positive practice environments in clinical settings. International Journal of Nursing Studies. 2014; 51(1): 85-92. PMid:23809644 https://doi.org/10.1016/j.ijnurstu. 201 3.05 .015

[22] Tuckett A, Eley R, Ng L. Transition to practice programs: What Australian and New Zealand nursing and midwifery graduates said. A Graduate eCohort Sub-Study. Collegian. 2017; 24(2): 101-108. https://doi.org/10.1016/j.colegn.2015.10.002

[23] Health Workforce Australia. Nurses in focus Australia's Health Workforce Series. 2013; 2-49. Adelaide: HWA.

[24] Gilmour J, Huntington A, Slark J, et al. Newly graduated nurses and employment: A dynamic landscape. Collegian. 2017; 24(3): 247-253. https://doi.org/10.1016/j.colegn.2016.02.004

[25] Lin P, Viscardi M, McHugh M. Factors influencing job satisfaction of new graduate nurses participating in nurse residency programs: a systematic review. Journal of Continuing Education in Nursing. 2014; 45(10): 439-450. PMid:25280192 https : //doi.org/10.3 928/00220124-20140925-15

[26] Bakon S, Craft J, Wirihana L, et al. An integrative review of graduate transition programmes: Developmental considerations for nursing management. Nurse Education in Practice. 2018; 2880-85. PMid:29045909 https://doi.org/10.1016/j.nepr . 2017.10 .009

[27] Parker V, Giles M, Lantry G, et al. New graduate nurses' experiences in their first year of practice. Nurse Education Today. 2014; 34(1): 150-156. PMid:22857819 https://doi .org/10.1016/j. nedt. 2012.07.003

[28] Woulfe T. Postgraduate study - to do or not to do? Kai Tiaki Nursing New Zealand. 2016; 22(10): 30-31.

[29] Coventry T, Maslin-Prothero S, Smith G. Organizational impact of nurse supply and workload on nurses continuing professional development opportunities: an integrative review. Journal of Advanced Nursing. 2015; 71(12): 2715-2727. PMid:26148213 https: //doi.org/10.1111/jan. 12724

[30] Hussein R, Everett B, Ramjan L, et al. New graduate nurses experiences in a clinical specialty: A follow up study of newcomer perceptions of transitional support. BMC Nursing. 2017. PMid:28775671 https://doi.org/10.1186/s12912-017-0236-0

[31] Fedele R. Generation next. Australian Nursing \& Midwifery Journal. 2016; 23(7): 16-21. https : //europepmc.org/article/med/27 032133

[32] Catholic Health Australia. Pastoral Care. 2018. https://www.cha. org.au/mission/pastoral-care

[33] Baldacchino D. Spiritual care education of health care professionals. Religions. 2015; 6: 594-613. https://doi.org/10.3390/rel6 020594

[34] MacPhee M, Dahinten V, Havaei F. The impact of heavy perceived nurse workloads on patient and nurse outcomes. Administrative Sciences. 2017; 7(1): 7. https://doi.org/10.3390/admsci7010 007

[35] Van Den Oetelaar W, Van Stel H, Van Rhenen W, et al. Balancing nurses' workload in hospital wards: Study protocol of developing a method to manage workload. BMJ Open. 2016; 6(11): e012148. PMid:28186931 https://doi .org/10.1136/bmjopen-2016-0 12148

[36] Maben J, Cornwell J, Sweeney K. In praise of compassion. Journal of Research in Nursing. 2009; 15(1): 9-13. https ://doi .org/10 $.1177 / 1744987109353689$

[37] Drayton N, Weston K. Exploring values in nursing: generating new perspectives on clinical practice. Australian Journal of Advanced Nursing. 2015; 33(1): 14-22. 